\title{
Climate effects on US infrastructure: the economics of adaptation for rail, roads, and coastal development
}

\author{
James E. Neumann ${ }^{1}$ (D) Paul Chinowsky ${ }^{2} \cdot$ Jacob Helman $^{2} \cdot$ Margaret Black $^{1} \cdot$ \\ Charles Fant ${ }^{1} \cdot$ Kenneth Strzepek ${ }^{1,3} \cdot$ Jeremy Martinich ${ }^{4}$
}

Received: 4 September 2019 / Accepted: 17 July 2021/ Published online: 19 August 2021

(C) The Author(s) 2021

\begin{abstract}
Changes in temperature, precipitation, sea level, and coastal storms will likely increase the vulnerability of infrastructure across the USA. Using models that analyze vulnerability, impacts, and adaptation, this paper estimates impacts to railroad, roads, and coastal properties under three infrastructure management response scenarios: No Adaptation; Reactive Adaptation, and Proactive Adaptation. Comparing damages under each of these potential responses provides strong support for facilitating effective adaptation in these three sectors. Under a high greenhouse gas emissions scenario and without adaptation, overall costs are projected to range in the $\$ 100$ s of billions annually by the end of this century. The first (reactive) tier of adaptation action, however, reduces costs by a factor of 10 , and the second (proactive) tier reduces total costs across all three sectors to the low $\$ 10$ s of billions annually. For the rail and road sectors, estimated costs for Reactive and Proactive Adaptation scenarios capture a broader share of potential impacts, including selected indirect costs to rail and road users, and so are consistently about a factor of 2 higher than prior estimates. The results highlight the importance of considering climate risks in infrastructure planning and management.
\end{abstract}

Keywords Rail $\cdot$ Roads $\cdot$ Coastal development $\cdot$ Infrastructure $\cdot$ Proactive adaptation

\section{Introduction}

Climate change is affecting infrastructure systems across the USA in far-reaching ways, and impacts are projected to worsen over time in many regions. Extreme temperature and

James E. Neumann

jneumann@indecon.com

1 Industrial Economics, Inc., Cambridge, MA, USA

2 Resilient Analytics, Inc. and University of Colorado, Boulder, CO, USA

3 Massachusetts Institute of Technology, Cambridge, MA, USA

4 U.S. Environmental Protection Agency, Washington, DC, USA 
precipitation events are damaging roadways and threatening the integrity of the rail system, as sea level rise (SLR) and storm surge (SS) erode our coastline and damage property and infrastructure, particularly during heavy storms which are occurring with greater frequency and intensity (US Global Change Research Program (USGCRP) 2017; Jacobs et al. 2018a; U.S. EPA 2017). These major infrastructure systems are critical to the nation's economy, security, and culture, as they facilitate commerce, transportation, and societal well-being.

Already, the US road and rail systems are in poor condition, with large portions exhibiting significant deterioration and in need of repair or replacement (ASCE 2017). Coastal infrastructure is also exceptionally vulnerable, with existing problems such as shoreline erosion, coastal flooding, and water pollution expected to worsen with climate change (Fleming et al. 2018). To address these challenges, engineers and infrastructure planners suggest a need to adapt the way we operate, maintain, upgrade, and expand the nation's infrastructure assets (ASCE 2018; U.S. DOT 2015).

Despite these challenges, limited literature exists that quantifies the vulnerability of US infrastructure to changes in climate and assesses the potential for adaptive action to mitigate these risks (Wang et al. 2020). The most recent National Climate Assessment (NCA) reinforces this point in multiple contexts. In the transportation context, NCA authors note that there are few studies that quantify the costs and benefits from adaptation, and those that exist focus on individual assets, rather than the system, and do not quantify both the direct and indirect economic costs of transportation system disruptions (Jacobs et al. 2018a). In the urban context, NCA authors note that while adaptation plans are becoming more common, those that directly incorporate climate projections into infrastructure design, investment and appraisal criteria, and model building codes are uncommon. As a result, adaptation planning is not always informed by technical analysis of changing hazards and climate vulnerability assessments (Maxwell et al. 2018). A similar situation exists in the coastal zone, where current adaptation plans call for risk identification, but there remains little focus on the cost-dependent tradeoffs required to successfully adapt (Fleming et al. 2018).

In this paper, we present the results of analyses quantifying impacts to three categories of infrastructure (rail, roads, and coastal property) across the USA. The analyses were conducted as part of the ongoing Climate Change Impacts and Risk Analysis (CIRA) project, which uses a consistent analytical framework of socioeconomic scenarios and climate projections to estimate and compare economic impacts across sectors and regions (U.S. EPA 2017). The use of a consistent framework and socioeconomic and climate inputs supports cross-sectoral comparison of results, an important and unique feature of the CIRA work (Martinich and Crimmins 2019). Here we choose to analyze three infrastructure sectors in a single paper in an effort to provide information useful in identifying vulnerable sectors and regions, as well to identify sectoral priorities for adaptation action. The analyses substantially update and expand on work previously published in the peer-reviewed literature (Chinowsky et al. 2013, 2017; Neumann et al. 2015a, 2015b; Lorie et al. 2020; U.S. Environmental Protection Agency (EPA) 2015, U.S. EPA 2017). In particular, the current analyses incorporate new scenarios that consider the effects of a "no adaptation" approach to infrastructure management and quantify costs in scenarios where adaptive measures are taken in response to climate change impacts ("reactive" adaptation) and in advance of impacts ("proactive" adaptation).

In addition to adding new scenarios that clarify the effect of adapting infrastructure to climate change, our work also provides a broader measure of economic impact than previous studies. Previous work focused on estimating direct costs to infrastructure associated with climate change (e.g., repair costs). While including these types of damages, our new analyses 
also incorporate estimates of selected indirect costs to users (e.g., delay costs and vehicle operating costs). Considering both direct and indirect costs is important to the evaluation of adaptation responses, and often there are tradeoffs between the two. For example, strategies to minimize adaptation costs may run the risk of underinvesting in infrastructure upkeep, reducing its serviceability and dramatically increasing user costs (as our "no adaptation" scenario shows for the road sector, considering both vehicle operating costs and the firstorder economic value of avoided transport delays). The inclusion of user costs also adds an important new dimension to evaluating adaptation options not previously assessed in a national scale analysis - the lack of estimates of indirect economic losses and alternative adaptation approaches recently have been identified as important omissions for climate impacts on the US rail and road system (Wang et al. 2020), which our work aims to address.

The remainder of the paper includes three sections. The next section reviews the common methods across all three infrastructure sectors analyzed, as well as methods specific to each. The section is supported by separate supplemental material for each of the three sectors. We then present results and conclude with a short discussion of the implications of this work and some suggestions for next research directions.

\section{Methods and data}

\subsection{Framework}

The rail, roads, and coastal property analyses presented herein employ a consistent analytic framework to evaluate the impacts of climate change under three alternative infrastructure management scenarios: No Adaptation, Reactive Adaptation, and Proactive Adaptation. The sector-specific applications of these management scenarios are discussed in the respective sectoral method sections below, but are described here in general terms, with the term "damage" defined as the physical manifestation of climate effects, for our purposes, and the term "cost" as the economic implication of either repairing damage or, in the case of user and indirect costs, of failing to repair the damage. The No Adaptation scenario represents a "business as usual" approach to infrastructure management which does not incorporate climate change risks into the maintenance and repair decision making process beyond baseline expectations. In the Reactive Adaptation scenario, decision makers respond to climate change impacts by repairing damaged infrastructure, but do not take actions to prevent or reduce future climate change impacts. In the Proactive Adaptation scenario, decision makers take adaptive action with the goal of preventing infrastructure repair costs associated with future climate change impacts. These actions often involve trading higher upfront expenditures for potential future benefits or savings. This Proactive Adaptation scenario assumes well-timed infrastructure investments, which may be overly optimistic given that such investments have oftentimes been delayed and underfunded in the past, and because decisionmakers and the public are typically not fully aware of potential climate risks. Finally, the framework adopted here largely follows that developed for Melvin et al. (2017) for the Reactive and Proactive scenario definitions-but the No Adaptation scenario provides additional useful context for the scale of risk-motivated action that would be required to adapt infrastructure in each sector. A summary of the overall response scenario framework is provided in Table 1. 
Table 1 Summary of costs included in the three adaptation scenarios

\begin{tabular}{|c|c|c|c|}
\hline & No Adaptation & Reactive Adaptation & Proactive Adaptation \\
\hline \multicolumn{4}{|l|}{ Rail } \\
\hline Costs include & $\begin{array}{l}\text { - Costs of replacing track to } \\
\text { repair lateral alignment } \\
\text { defects in the buckling zone } \\
\text { and costs of re-aligning rail } \\
\text { in adjoining zones } \\
\text { - Costs of delays that occur due } \\
\text { to track buckling and repair }\end{array}$ & $\begin{array}{l}\text { - Costs of replacing track to } \\
\text { repair lateral alignment } \\
\text { defects in the buckling zone } \\
\text { and costs of re-aligning rail } \\
\text { in adjoining zones } \\
\text { - Costs of delays that occur due } \\
\text { to track buckling and repair, } \\
\text { as well as delays associated } \\
\text { with blanket speed } \\
\text { reductions }\end{array}$ & $\begin{array}{l}\text { - Costs of purchasing, } \\
\text { installing, and maintaining } \\
\text { the track temperature } \\
\text { sensors, and related } \\
\text { software infrastructure } \\
\text { - Costs of delays associated } \\
\text { with risk-based speed re- } \\
\text { ductions }\end{array}$ \\
\hline $\begin{array}{l}\text { Costs do not } \\
\text { include }\end{array}$ & $\begin{array}{l}\text { - Costs of derailment that may } \\
\text { result from track buckling } \\
\text { - Costs of routine (non-climate } \\
\text { driven) track maintenance, } \\
\text { including winter mainte- } \\
\text { nance }\end{array}$ & $\begin{array}{l}\text { - Costs of derailment that may } \\
\text { result from track buckling } \\
\text { - Costs of developing and } \\
\text { implementing the speed } \\
\text { orders } \\
\text { - Costs of routine (non-climate } \\
\text { driven) track maintenance }\end{array}$ & $\begin{array}{l}\text { - Costs of routine (non-climate } \\
\text { driven) track maintenance }\end{array}$ \\
\hline \multicolumn{4}{|l|}{ ROADS } \\
\hline Costs include & $\begin{array}{l}\text { - Repair costs, limited to } \\
\text { historical spending, with } \\
\text { priority given to repairing } \\
\text { damage from extreme } \\
\text { precipitation and } \\
\text { precipitation } \\
\text { - Costs of delays due to repairs } \\
\text { and due to increased IRI } \\
\text { - Vehicle operating costs } \\
\text { (VOCs) }\end{array}$ & $\begin{array}{l}\text { - Repair costs } \\
\text { - Costs of delays due to repairs }\end{array}$ & $\begin{array}{l}\text { - Upfront capital costs of } \\
\text { proactive strengthening } \\
\text { - Repair costs } \\
\text { - Costs of delays due to } \\
\text { proactive strengthening and } \\
\text { repairs. }\end{array}$ \\
\hline $\begin{array}{l}\text { Costs do not } \\
\text { include }\end{array}$ & $\begin{array}{l}\text { - Routine (non-climate driven) } \\
\text { maintenance costs, includ- } \\
\text { ing winter road clearing } \\
\text { - Costs associated with roads } \\
\text { that are closed due to } \\
\text { extreme disrepair }\end{array}$ & $\begin{array}{l}\text { - Routine (non-climate driven) } \\
\text { maintenance costs }\end{array}$ & $\begin{array}{l}\text { - Routine (non-climate driven) } \\
\text { maintenance costs }\end{array}$ \\
\hline \multicolumn{4}{|c|}{ Coastal Property } \\
\hline Costs include & $\begin{array}{l}\text { - The property values of } \\
\text { abandoned properties and } \\
\text { the structure damage from } \\
\text { SS flooding (calculated as a } \\
\text { percentage of the property } \\
\text { value). }\end{array}$ & $\begin{array}{l}\text { The property values of } \\
\text { abandoned properties, } \\
\text { structure damage from SS } \\
\text { flooding, and costs of } \\
\text { elevation. }\end{array}$ & $\begin{array}{l}\text { - The property values of } \\
\text { abandoned properties and } \\
\text { the costs of protection } \\
\text { where it is warranted. }\end{array}$ \\
\hline $\begin{array}{l}\text { Costs do not } \\
\text { include }\end{array}$ & $\begin{array}{l}\text { - Direct measure of damage to } \\
\text { public infrastructure. } \\
\text { - Indirect costs associated with } \\
\text { flooding (i.e., business } \\
\text { interruptions or secondary } \\
\text { impacts of loss of critical } \\
\text { infrastructure). }\end{array}$ & $\begin{array}{l}\text { - Direct measure of damage to } \\
\text { public infrastructure. } \\
\text { - Indirect costs associated with } \\
\text { flooding (i.e., business } \\
\text { interruptions or secondary } \\
\text { impacts of loss of critical } \\
\text { infrastructure). }\end{array}$ & $\begin{array}{l}\text { - Direct measure of damage to } \\
\text { public infrastructure. } \\
\text { - Indirect costs associated with } \\
\text { flooding (i.e., business } \\
\text { interruptions or secondary } \\
\text { impacts of loss of critical } \\
\text { infrastructure). }\end{array}$ \\
\hline
\end{tabular}




\subsection{Climate projections}

The climate projections were selected to be consistent with those used in the Fourth NCA (USGCRP 2017). The analyses used Representative Concentration Pathway (RCP) 8.5 as a higher greenhouse gas emissions scenario and RCP 4.5 as a lower scenario. The RCPs are identified by their total approximate radiative forcing (in watts per square meter) in the year 2100 relative to 1750 . The analyses employed five global climate models (GCMs) selected based on criteria detailed in U.S. EPA (2017) and the associated technical appendix. The five models applied here were from the Canadian Centre for Climate Modeling and Analysis (CanESM2); the National Center for Atmospheric Research (CCSM4); the NASA Goddard Institute for Space Studies (GISS-E2-R); the Meteorological Office at the Hadley Centre (HadGEM2-ES); and the Atmosphere and Ocean Research Institute, National Institute for Environmental Studies, and Japan Agency for Marine-Earth Science and Technology (MIROC5).

The analyses use 20-year climatic time periods to ensure that results for any single year do not over- or underrepresent the characteristics of a future period from any of the five models. Results for the 20-year eras are represented using the central year in each period: 2030 (20202039); 2050 (2040-2059); 2070 (2060-2079); and 2090 (2080-2099). The baseline scenario, 1986-2005, is designed to reflect current climatic conditions.

The ten combinations of RCPs and GCMs were downscaled from the native GCM spatial resolution to a 1/16-degree resolution covering the contiguous USA. The dataset, called LOCA (which stands for localized constructed analogs), features a statistical downscaling technique using a multi-scale spatial matching scheme to pick appropriate analog days from observations. The LOCA dataset provides daily projections through 2100 for three variables: daily maximum temperature $\left(t_{\max }\right)$, daily minimum temperature $\left(t_{\min }\right)$, and daily precipitation (see US Bureau of Reclamation 2016 and supplemental materials for more details and download link). Projections of SLR and SS for each RCP are based on NOAA (2018) and Sweet et al. (2017). All analyses reflect adjustments over time for population and economic growth, including adjustments to traffic volume for the rail and road sectors, and adjustments to property value for the coastal property sector. Details are provided below and in the supplemental material.

\subsection{Rail}

Chinowsky et al. (2017) estimated the impacts of projected changes in temperature on the currently existing (as of 2015) Class 1 rail network in the USA. Specifically, this work analyzed a Reactive Adaptation scenario in which operators implement "blanket" speed restrictions during periods of high temperature to avoid track buckling events, and a Proactive Adaptation scenario in which operators use track temperature sensors to optimize their speed restrictions. The analysis estimated the costs of delays in each scenario, along with the capital costs of installing sensors in the Proactive Adaptation scenario.

The current analysis expands on the 2017 work by estimating repair and delay costs in a No Adaptation scenario in which operators do not reduce speeds when temperatures increase, resulting in an increased risk of track buckling. There is also a potential for track buckling to cause train derailment, but recent literature suggests that less than four percent of derailments are caused by buckled track (Liu, Saat, and Barkan, 2012). We therefore do not model derailments or associated costs and damages, which may result in an underestimate of costs for the No Adaptation scenario. 
We estimate the number of track buckling events using Equation (1) (Kish and Samavedam 2013):

$$
e_{b}=\left(P_{b} \times P_{T} \times n_{t} \times 365 \times L\right) /\left(L_{t}\right)
$$

where

$P_{b} \quad$ probability of buckling at rail temperature

$P_{t} \quad$ annual rail temperature frequency

$n_{t} \quad$ number of trains per day

$L \quad$ total length of track

$L_{t} \quad$ length of train

We assume that $P_{b}$ increases exponentially between $T_{b, \min }$ and $T_{b, \max }$ based on work by the Volpe Center, Foster-Miller, Inc. (FMI), and the Federal Railroad Administration (FRA) as part of the CWR-SAFE program, described in Appendix C of Kish and Samavedam (2013). Additional details on this approach are provided in the Supplementary Material.

We estimate costs of repairing damage associated with buckling events, including (1) costs of replacing track to repair lateral alignment defects in the buckling zone and (2) costs of realigning rail in adjoining zones. Based on national average cost data, we estimate that repairs for each track buckling event would take $14 \mathrm{~h}$ and cost \$21,000 (Gordian 2017). By comparison, a UK study estimated that the average repair cost associated with a buckling event is $£ 10,000$ (approximately $\$ 15,000$ ) (Hall and Jenkins n.d.). Delay costs associated with track buckling events are difficult to estimate due to the lack of publicly available data. For freight traffic, we follow the approach described in Chinowsky et al. (2017). However, we do not quantify costs associated with emissions for trains that are stopped for repair of buckling events because there would be no locomotive emissions. For passenger rail, we assume that passengers would de-board trains that are stopped due to a buckling event and find an alternative mode of transportation to reach their destination, with an estimated total delay time of $8 \mathrm{~h}$. To quantify the costs of passenger delay, we rely on DOT's 2016 guidance for the valuation of travel time in economic analysis (U.S. DOT 2016).

In the Reactive Adaptation scenario, we assume that train operators implement speed orders that result in blanket speed reductions for operations occurring in areas where the expected daily high exceeds a temperature that is deemed unsafe, consistent with their on-the-books policies. We estimate train delay from extreme heat events according to our 2017 work. Traindelay minutes are calculated at a grid level in accordance with the granularity of the climate projections. Since impacts are limited to estimates at the grid level, impacts are averaged over the inventory in that grid cell to reflect the granularity of the projection. In this grid approach, the generalized approach is summarized as follows:

$$
\mathrm{TDM}_{g}=\left({ }^{L_{g}} / S_{r}-{ }^{L_{g}} / S_{o}\right) \times 60 \times\left(H_{d} / H_{o}\right)
$$

where

$\mathrm{TDM}_{g} \quad$ train delay minutes per grid

$S_{r} \quad$ reduced speed

$S_{0} \quad$ base speed

$L_{g} \quad$ total length of rail traveled per grid 
$H_{d} \quad$ hours of speed order

$H_{\mathrm{o}} \quad$ hours of railroad operation

In this method, train delay minutes are first calculated based on a speed restriction, the length of track in the grid, and the number of hours in which the speed order will be put into effect.

Once the total delay minutes are calculated on a per grid basis, the delay minutes per year are calculated by multiplying the delay minutes per grid by the average volume of trains per grid and the number of incident days per grid (defined as a day in which a speed order is put into place). Finally, the delay minutes are quantified as costs using a unit cost per minute of delay, referenced in the supplemental material.

Additionally, we update the methods to incorporate estimates of track buckling in this scenario because, although blanket speed orders reduce the probability of track buckling, they do not eliminate them. In the Proactive Adaptation scenario, we assume train operators install track temperature sensors which enable them to use a risk-based approach to speed orders. A reduction in speed to avoid buckling is calculated based on temperatures using Eq. 3 (Kish and Samavedam 2008).

$$
\frac{V_{r}}{V_{\max }}=\left(1-\frac{P_{b}(T)}{P_{b}\left(T_{L}\right)}\right) .5
$$

where

$V_{r} \quad$ reduced speed

$V_{\max } \quad$ permissible maximum authorized line speed

$P_{b}(T) \quad$ buckling probability at track temperature, $T$

$P_{b}\left(T_{L}\right) \quad$ buckling probability at limiting temperature, $T_{L}$

The limiting temperature for track safety is therefore the maximum allowable temperature ( $\left.T_{\text {allowable }}\right)$ above the neutral temperature of the rail.

We assume that the risk-based approach reduces the probability of a track buckling event to zero. The costs in this scenario include the costs of purchasing, installing, and maintaining the track temperature sensors, and related software infrastructure, as described in Chinowsky et al. (2017). In addition, we estimate the costs of delay associated with risk-based speed reductions.

\subsection{Roads}

Our previous analysis of the current US roads network focused on evaluating the potential impacts of climate change in a Reactive Adaptation scenario, in which roads are repaired (to maintain service levels) in response to climate change-related damage, and in a Proactive Adaptation scenario, in which roads are protected and rehabilitated to prevent future impacts from climate stressors (U.S. EPA 2017). The current analysis expanded on this work by incorporating estimates of the costs to road users, quantified as delay costs and vehicle operating costs (VOCs).

We developed a No Adaptation scenario in which decision makers limit their annual spending on repairs due to climate change costs to what they spent historically (in the period 1986-2005). We assume that in making repairs, road managers prioritize repairs related to damage from extreme precipitation and precipitation (as opposed to temperature) since these 
damages are more severe and require attention in the current fiscal year. Once the damages from precipitation are addressed, the remaining budget is then used to repair temperature-based damages. In the case where precipitation damage remains, the continuation of these damages is not currently modeled due to a lack of previous research on which a generalized damage function can be based. However, in most cases, the remaining budget is used to address temperature damages. If repair costs exceed the budget, we model the potential for continued damage to roads by measuring the increased roughness using the international roughness index or "IRI."

Based on research by Qiao et al. (2013), we developed a generalized correlation between temperature increase and rutting, which assumes that rut depth increases gradually and linearly over the life span of the road, and that in a year in which the average temperature increases by $5 \%$ (a climate stressor measure that is consistent with the underlying literature), there will be an additional 0.04 inches of rutting. Then we translate the estimated rut depth to IRI using a model from the Guide for Mechanistic-Empirical Design of New and Rehabilitated Pavement Structures (ARA, Inc. 2001) using Eq. 4:

$$
\mathrm{IRI}=57.56 \times R D^{-334}
$$

where

IRI smoothness in $\mathrm{cm} / \mathrm{km}$

$\mathrm{RD}$ rut depth, mm

We then estimate the costs associated with increased IRI, which include (1) increased VOCs resulting from driving on damaged roads, based on research by Barnes and Langworthy (2004), and (2) delays from vehicles traveling at reduced speeds to navigate damaged roads, based on research by Wang et al. (2013). Barnes and Langworthy detail the VOCs for 3 types of vehicles, automobile, pickup/van/SUV, and commercial truck for each VOC category. Two sets of VOCs were estimated for a smooth pavement and a poor pavement quality-we average the results.

Using this relationship and traffic values, the total change in VOC for a given road was estimated. Grid level traffic data was estimated using national and state level traffic census programs. Traffic was split into average daily traffic (ADT) and average daily truck traffic (ADTT). The annual VOCs for a road segment are calculated using Eq. 5:

$$
\text { Annual } \mathrm{VOC}=\frac{\mathrm{VOC}_{\text {unit }}}{100} \times \mathrm{ADT} \times L \times 365
$$

where

$\mathrm{VOC}_{\text {unit }}$ unit vehicle operating cost for vehicle type (cents/mile)

$L \quad$ length of road (miles)

ADT average daily traffic (vehicles per day)

Various studies have quantified the effect of roughness on travel speed. We rely on a California Department of Transportation study that found that a one unit change in IRI leads to a $0.48-\mathrm{km} / \mathrm{h}$ change in free-flow speed (Wang et al. 2013). Although these changes in freeflow speed are small relative to the posted speed limits, there can still be a significant impact on delay when considering across the entire US road system. Using this relationship between 
IRI and free-flow speed, the decrease in speed was calculated for PSR values - the conversion from IRI to PSR is described in the supplemental material. The cost of delay from change in free-flow speed can be calculated for a given road using Eq. 6:

$$
\text { Total cost of delay }=\left(\frac{L}{V-\Delta V}-\frac{L}{V}\right) \times \mathrm{ADT} \times 365 \times C_{D}
$$

where

$L \quad$ length of road (miles)

$V \quad$ posted speed limit

$\Delta V \quad$ change in free-flow speed

ADT average daily traffic (vehicles per day)

$C_{D} \quad$ unit cost of delay (USD/vehicle-hour)

To estimate delay for the Reactive and Proactive Adaptation scenarios, we utilized national and state DOT productivity rates to estimate the disruption time for various types of road work associated with stressor-related maintenance and adaptation, as described in the supplemental material.

To account for the potential for vehicles to avoid damaged roads or roads undergoing repair work, we developed an index representative of redundancy in the road network. Specifically, we developed ratios for each 0.25 -degree grid cell of road infrastructure to population and normalized the ratios on a scale from zero to one, and then multiplied them by our estimated delay time to account for redundancy. To quantify the costs of delay for passenger vehicle travel, we rely on the value of travel time savings estimates from U.S. DOT (2016). To quantify the cost of delay for freight vehicle travel, we rely on data from the National Cooperative Highway Research Program (NCHRP) that are used as inputs to their Truck Freight Reliability Valuation Model (NCHRP 2016).

\subsection{Coastal property}

The coastal analysis builds on a long-standing framework, the National Coastal Properties Model (NCPM; Lorie et al. 2020; Neumann et al. 2015b), which assesses SLR and SS risks to the existing footprint of coastal development. Since the last published description, modifications have been made to the NCPM. These include updating SLR projections, updating SS heights, improving the adaptation decision rules, and improving model initialization. These four modifications are described briefly below. More detail on these, as well as an update to property values, is described in the Supplementary Material.

\subsubsection{Sea level rise projections}

For the Fourth NCA, Sweet et al. (2017a) developed a set of six global SLR scenarios that used the Kopp et al. (2014) projections to tie global scenarios to regional sea level changes. The six scenarios project increases in global mean sea level (GMSL) between 2000 and 2100 of $0.3 \mathrm{~m}, 0.5 \mathrm{~m}, 1.0 \mathrm{~m}, 1.5 \mathrm{~m}, 2.0 \mathrm{~m}$, and $2.5 \mathrm{~m}$. For this analysis, we use these 1-degree gridded projections from Sweet et al. (2017a) by aggregating to the county-level. Of the three uncertainty scenarios - low, medium, high — we use the medium. Results for all six GMSL rise scenarios are developed, but we use probabilities associated with each (see Sweet et al. 2017a), which vary by RCP, to aggregate GMSL results. 


\subsubsection{Storm surge probabilities}

Rising sea levels will increase the severity of flooding by raising the baseline water level over which storms and other high water level events create a surge. For this analysis, we use historical tide gauge measurements (NOAA 2018), which allow direct estimation of SS for all 302 coastal counties in our domain. We extracted the maximum daily water level from each record, and de-trended the resulting set of maximum gauge heights from each time series - we then calculated a distribution of SS heights by fitting a generalized extreme value distribution to the annual maximum time series from each gauge, providing an estimate of the surge heights associated with return intervals from 2 to 500 years. Tide gauges with less than 10 years of data were excluded. Stations were matched to counties using proximity and topography.

\subsubsection{Protection decision rules}

Decision rules for adaptation to episodic flooding caused by SS, which rises as sea levels rise, were reformulated from Neumann et al. (2015b) to enable a traditional cost-benefit test - these are described in further detail in Lorie et al. (2020) and in the Supplementary Material for the NCPM. New rules compare the cost of different adaptation options within each cell to the expected reduction in costs that would result from those adaption options. This decision rule is based on an estimate of the cost of expected annual damages (EAD) and expected annual benefits of adaptation. EAB is the avoided damage cost given the assumption that adaptation will prevent damage for events up to and including the current 100-year flood. In its simplest form, the decision rule implements the lowest cost adaptation option.

\subsubsection{Model initiation}

Comprehensive data on existing SS protection (sea walls, elevated structures) across CONUS, to our knowledge, is not available. To identify where sea walls and elevated structures may already exist, we run the NCPM over an initiation period prior to the simulation. This technique is also called model "spin-up" and is often used in dynamic models to provide a consistent starting point for each simulation - spin-up was used in Lorie et al. 2020). Model initiation allows for the most cost-effective protection during model initiation, with all options available independent of the adaptation scenario. Spin-up costs are excluded in the reported costs.

\subsubsection{Coastal adaptation scenarios}

For the No Adaptation scenario, no protective measures are implemented to avoid the impacts of SLR and SS (see Table 1 for a summary). As a result, properties incur damage (inundation from SLR and flooding from SS). We assume that property owners abandon properties that are inundated by SLR and that they incur damage from SS flooding. If the costs of damage associated with SS exceed the value of the property, we assume that the property owner abandons the property. For this scenario, costs include the property values of abandoned properties and the structure damage from SS flooding (calculated as a percentage of the property value); but in this (and all scenarios), they exclude any direct measure of damage to public infrastructure, indirect costs associated with flooding (i.e., business interruptions or 
secondary impacts of loss of critical infrastructure), losses of marsh and other coastal ecosystems, and recreation value lost from loss of beaches, except as implicitly capitalized in diminished property value.

Similar to No Adaptation scenario, under Reactive Adaptation scenario, property owners do not implement protective measures to avoid SLR impacts. When a property is inundated by SLR, we assume the property owner abandons the property. When SS damages occur, however, we assume that the property owner evaluates whether or not to elevate the property to avoid future damage. This is done by multiplying the damage in the current year by 10 to estimate the decadal cost of damage. If the projected decadal cost of damage is greater than the property value, the property is abandoned. If the projected cost of damage is less than the property value, and also less than the costs of elevating, then the property incurs the cost of damage. If the projected cost of damage is less than the property value, but greater than the costs of elevation, then the property elevates. We assume that shoreline armoring is not implemented in this scenario, as this activity typically requires planning in advance by states or the Federal government, and thus is better characterized as Proactive Adaptation scenario. Costs in Reactive Adaptation scenario therefore include the property values of abandoned properties, structure damage from SS flooding, and costs of elevation where it is warranted.

In the Proactive Adaptation scenario, protective measures are implemented to avoid damage from both SLR and SS. These measures include beach nourishment, armoring, elevation, and abandonment. In this scenario, costs include the property values of abandoned properties and the costs of all forms of protection where it is warranted (see Table 1). The NCPM selects the least-cost option on an annual basis in response to sea level rise and on a decadal basis in response to storm surge. Additional information on the decision tree logic and other sources of information used in the NCPM is included in the Supplemental Material.

\section{Results}

Table 2 presents the average annual change in costs in 2050 and 2090 relative to the baseline period (1986-2005) under RCP8.5 and RCP4.5 for the three sectors. Across all sectors and in both time periods, the estimated average cost increases are greatest under the No Adaptation scenario and lowest under the Proactive Adaptation scenario, as expected. We also see reductions in cost under RCP4.5 relative to RCP8.5 across all infrastructure types and in both time periods.

At the national (CONUS) level, these results differ from those presented for comparable scenarios in prior work that uses these modeling tools, as described in USEPA (2017, see Table 29.2 on page 214), but in ways that directly reflect the methodological improvements outlined above to broaden the scope of estimated impacts and to refine the climate scenario inputs (e.g., new storm surge modeling in the coastal property analysis). For the rail and road sectors, the estimates presented here for Reactive and Proactive Adaptation scenarios have comparable patterns across time and climate scenarios, but are consistently about a factor of 2 higher, owing to the inclusion here of not just the direct costs of repair actions, but also the indirect effects associated with traffic delay. The No Adaptation scenario case for rail and roads is new to this work, and for roads in particular, it makes clear that the risk of inaction is extraordinarily high compared to prior estimates - most of the difference between No Adaptation and Reactive Adaptation scenarios for roads reflects costs to road users, in the form of delays and damage to vehicles associated with incomplete road repair and/or the failure to invest in climate resilience during rehabilitation cycles. 
Table 2 Average annual change in costs relative to the baseline (1986-2005) (5-GCM average, billions \$2018, undiscounted)

\begin{tabular}{|c|c|c|c|c|}
\hline \multirow[t]{2}{*}{ Infrastructure sector and scenario } & \multicolumn{2}{|l|}{2050} & \multicolumn{2}{|l|}{2090} \\
\hline & RCP8.5 & RCP4.5 & RCP8.5 & RCP4.5 \\
\hline \multicolumn{5}{|l|}{ Rail } \\
\hline No Adaptation & $\$ 11.3$ & $\$ 5.8$ & $\$ 45.4$ & $\$ 8.5$ \\
\hline Reactive Adaptation & $\$ 10.2$ & $\$ 5.4$ & $\$ 35.9$ & $\$ 6.6$ \\
\hline Proactive Adaptation & $\$ 0.9$ & $\$ 0.4$ & $\$ 3.3$ & $\$ 0.7$ \\
\hline \multicolumn{5}{|l|}{ ROADS } \\
\hline No Adaptation & $\$ 158.6$ & $\$ 100.4$ & $\$ 432.7$ & $\$ 181.7$ \\
\hline Reactive Adaptation & $\$ 19.0$ & $\$ 13.1$ & $\$ 45.3$ & $\$ 17.8$ \\
\hline Proactive Adaptation & $\$ 9.0$ & $\$ 8.3$ & $\$ 5.1$ & $\$ 4.0$ \\
\hline \multicolumn{5}{|l|}{ Coastal Property } \\
\hline No Adaptation & $\$ 8.9$ & $\$ 7.4$ & $\$ 44.1$ & $\$ 21.1$ \\
\hline Reactive Adaptation & $\$ 5.5$ & $\$ 5.1$ & $\$ 23.9$ & $\$ 11.2$ \\
\hline Proactive Adaptation & $\$ 5.9$ & $\$ 5.3$ & $\$ 7.8$ & $\$ 6.8$ \\
\hline
\end{tabular}

Note: All estimates in this table are net of baseline costs, so only the costs of climate change above those incurred for historic climate are shown. For context, baseline costs for historic climate are estimated to be between $\$ 0.5$ and $\$ 0.8$ billion for rail and $\$ 11.8$ billion for roads. Coastal property results are estimated from a zero baseline. All estimates adjusted for population and GDP growth over the simulation period

The No Adaptation scenario national level coastal results, on the other hand, are much lower from those in U.S. EPA (2017), based mostly on the exclusion of initial early armoring costs for the No Adaptation scenario case during the "spin-up" phase (these are about $\$ 67$ billion for all scenarios), but also owing to changes in our SS scenario inputs. The NCPM estimates for Florida, in particular, are quite sensitive to differences in SS scenarios. The use of the historic tide gauge-based inputs in this work, rather than the Emanuel (2013) results in prior work, avoids the need to extrapolate results from modeled counties to non-modeled counties, but also ignores the storm intensifying effect of climate change over time. Examination of SS exceedance curves used as inputs suggests that the new approach used here adds detail and precision at the low intensity end of the curve (the 1- to 10-year return period) but yields lower surges at the high intensity end (100- and 500-year return period), an effect that is expected (USGCRP 2017). What is revealed in this work is that sites in Florida, in particular the Miami area, are very sensitive to these changes in SS inputs. At the national level, however, the net effect of these changes on the full adaptation results is small and almost negligible, but the effect on the No Adaptation scenario results is to reduce them by about 63 to $77 \%$ in 2090 .

The national level results are discussed further in Section 4 -in the remainder of this section, we present more detailed results for each of the three sectors.

\subsection{Rail}

The results indicate that climate change is expected to result in a large increase in costs to the rail sector by the end of the century, particularly in the No Adaptation scenario under RCP8.5. Under the No Adaptation scenario, the number of buckling events is projected to increase which will lead to additional repairs and delay costs. Under the Reactive Adaptation scenario, the number of blanket speed orders is projected to increase which leads to an increase in speed order delay costs but does help to limit the number of buckling events compared to the No 
Adaptation scenario. Under the Proactive Adaptation scenario, the number of risk-based speed orders is projected to increase which leads to an increase in speed-order delay costs. However, the effectiveness of the risk-based speed orders dramatically reduces the delay cost compared to the Reactive Adaptation scenario blanket speed order.

Costs in the Proactive Adaptation scenario are roughly an order of magnitude lower than costs in the Reactive and No Adaptation scenarios in both time periods and under both RCPs. In 2050, the Proactive Adaptation scenario has an average annual savings of $\$ 5.40$ and $\$ 5.00$ billion compared to the No Adaptation and Reactive Adaptation scenarios. By 2090, those savings increase to $\$ 7.80$ and $\$ 5.90$ billion annually. Proactive savings are driven by the large reduction in buckling events and a reduction in speed-order delay costs from a risk-based approach to speed orders. In addition, costs under RCP8.5 are five times higher than costs under RCP4.5 by the end of the century, and two to three times higher in the mid-century period.

The map in Figure 1 displays the change in costs to the US rail network under RCP8.5 in 2090 relative to the baseline (1986-2005) - the more extreme RCP8.5 is shown in this figure, as well as others in this section, to better highlight differences in impact across space. As shown, grid-level costs are projected to be highest in the No Adaptation scenario, and costs in the Proactive Adaptation scenario are comparatively much lower. In general, the highest costs are projected to occur in the Southeast and Midwest.

\subsection{Roads}

As shown in Table 2, climate change is projected to result in significant cost increases in the roads sector in the No Adaptation scenario, with average annual costs under RCP8.5 estimated at $\$ 343.4$ billion by 2090 . In both time periods, cost increases are greater under RCP8.5 relative to RCP4.5, particularly at the end of the century. Interestingly, although costs increase under both RCPs over time in the No Adaptation and Reactive Adaptation scenarios, they decrease under the Proactive Adaptation scenario, suggesting that planning for climate changerelated damage can decrease costs in the future in this sector.

Figure 2 shows the distribution of the changes in costs across the contiguous USA under RCP8.5 in 2090 relative to the baseline. As shown, costs are highest in the No Adaptation scenario and are generally concentrated in the eastern half of the USA, consistent with spatial patterns of denser development. In the Proactive Adaptation scenario, some areas of the country experience cost savings relative to the baseline, with the remainder of the country experiencing relatively low increases in costs compared to the No Adaptation and Reactive Adaptation scenarios. For gravel and unpaved roads, precipitation-related costs are higher with proactive adaptation than with reactive adaptation. This is because the options for proactively adapting unpaved roads to increased precipitation risks are limited to upgrading the roads to paved or gravel, which are both very expensive. Proactive adaptation for gravel roads is also very expensive, as it essentially involves reconstructing the road with enhanced structural capacity. In summary, then, proactive adaptation reduces temperature and precipitationrelated costs for the paved road network, which when combined with the reduced costs in some areas due to temperature changes, results in proactive estimates being less than baseline costs.

Among the three climate stressors, economic impacts that result from temperature stress dominate the No Adaptation scenario case, accounting for $90 \%$ of the cumulative "all stressor" 

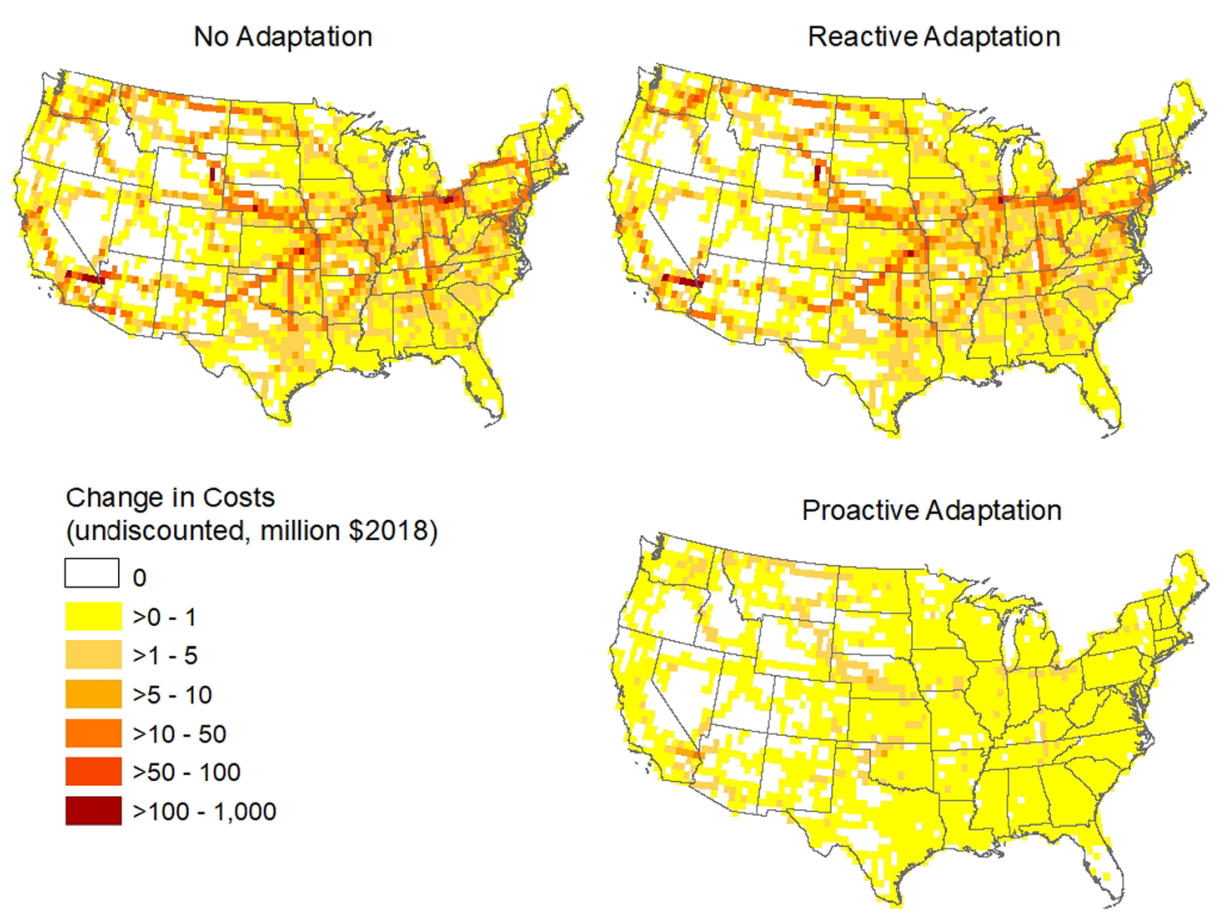

Fig. 1 Change in costs to the U.S. rail network in 2090 relative to baseline (1986-2005) under RCP8.5 (undiscounted, \$2018)

impact for RCP4.5, and 95\% for RCP8.5. The main reason for this possibly surprising result is the large indirect user costs that result from unrepaired temperature-induced rutting over potentially large areas of the US road network. The detailed results for the temperature stressor alone, summarized in Table 3, also reveal other interesting findings. First, baseline costs for a historical climate, simulated for the full 2018-2099 period and discounted to 2018, are actually lower for temperature than they are for other stressors (the highest baseline cost are for flooding, not shown in the table, which we believe is consistent with experience based on culvert failure frequency in current climate relative to temperature-induced rutting). Second, the case for adaptation to temperature stress, in the aggregate, is extremely strong, largely because user costs are so high in the No Adaptation scenario case, and they are largely eliminated in the Proactive scenario. This means we can expect current road budgets will quickly become inadequate to deal with temperature stress, and they need to be augmented to finance adaptive measures. Third, results for the temperature stressor display wide variation by GCM, which is generally much smaller for impacts from other stressors. The No Adaptation scenario results show an order-of-magnitude variation across GCMs. Adaptation substantially reduces this variation, to about a factor of 4 across GCMs in the Reactive scenario, and to a factor of 1.6 across GCMs in the Proactive scenario. The encouraging finding is that adaptation is robust to climate variation, suggested that there are minimal regrets associated with investing in roads that are more resilient to future temperature changes - even if that investment will require augmented financing to ensure sufficient capital budgets in the short term provide long-term resiliency payoff of foresight (acknowledging that some of that payoff accrues to road users). 

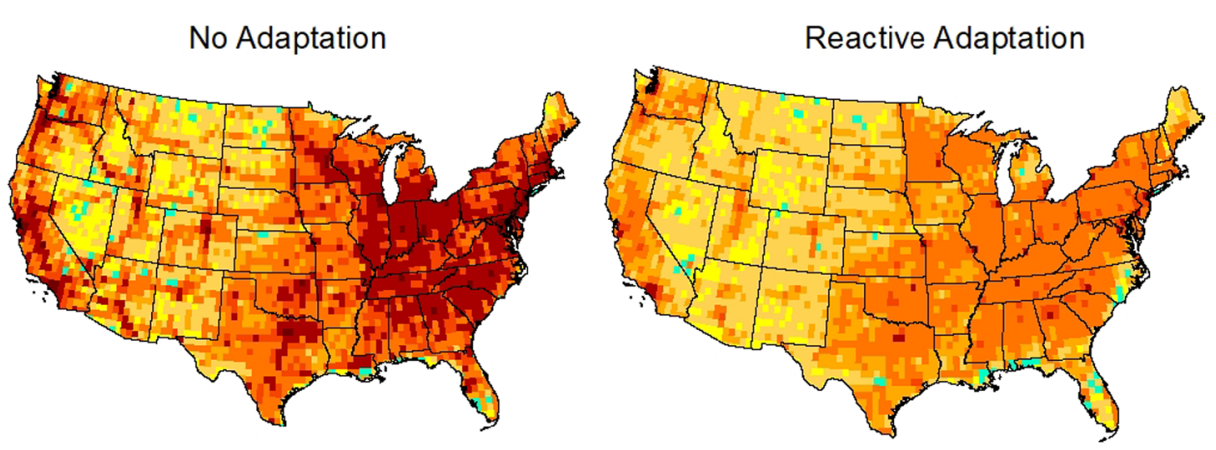

Change in Costs (undiscounted, million \$2018)
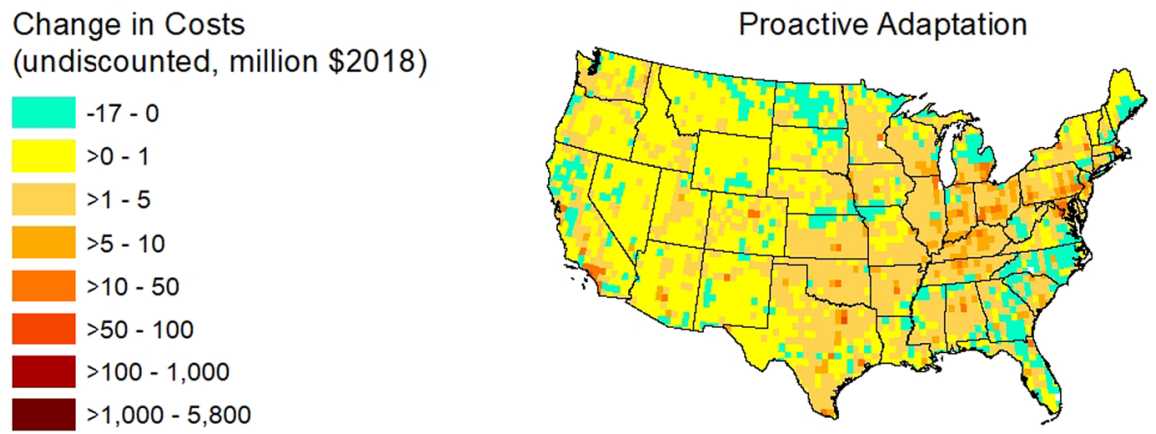

Fig. 2 Change in costs to the U.S. roads sector in 2090 relative to baseline (1986-2005) under RCP8.5 (undiscounted, million \$2018)

\subsection{Coastal property}

Coastal property costs rise steeply from 2050 to 2090 for No Adaptation scenario; they are five times higher for RCP8.5 and almost triple for RCP4.5. However, under a Proactive Adaptation scenario, the annual costs only rise about $\$ 1.5$ to $\$ 1.9$ billion (about $30 \%$ for both RCPs) between the two eras. Differences between the Proactive and Reactive Adaptation scenarios are negligible in 2050, but by 2090, savings are much more apparent between the two, more than $\$ 20$ billion per year under RCP8.5.

Coastal regions in CONUS are impacted differently for various reasons - in particular, the relationship among property locations, topology, and variations in the rates of regional SLR. Also, these costs are extensively dependent on the timing of vulnerability. For example, if a property is abandoned in 2030, costs for the abandonment occur in 2030 but that property is no longer subject to damages from SS for the remainder of the century. Some of these characteristics are explored in Figure 3, which shows these costs over time for RCP8.5, on an era basis, for four coastal regions: Pacific, North Atlantic, South Atlantic, and the Gulf (note differences in $y$-axis scales).

In 2030 and 2050, costs are highest in the Gulf for No Adaptation scenario, followed by the South Atlantic. In 2070 and 2090, costs in the South Atlantic rise to almost $\$ 600$ billion per year by 2090 under the No Adaptation scenario. Three neighboring counties in southern Florida-Miami Dade, Broward (Ft. Lauderdale), and Palm Beach — account for over $80 \%$ of the total costs in the South Atlantic region, and are the three counties with the highest costs in contiguous USA. These costs are largely driven by SLR in the latter half of the century. The 
Table 3 Roads sector cost results for temperature climate stressor, by GCM and RCP (cumulative net present value of costs over period 2018-2099, discount rate 3\%, billions \$2018)

\begin{tabular}{llll}
\hline Emissions scenario and GCM & No Adaptation & Reactive Adaptation & Proactive Adaptation \\
\hline $\begin{array}{l}\text { Baseline } \\
\text { Historic climate }\end{array}$ & $\$ 27$ & $\$ 27$ & \\
RCP4.5 & & & $\$ 57$ \\
CanESM & $\$ 1050$ & $\$ 176$ & $\$ 124$ \\
CCSM4 & $\$ 1363$ & $\$ 195$ & $\$ 123$ \\
GISSE2R & $\$ 467$ & $\$ 101$ & $\$ 105$ \\
HadGEM2ES & $\$ 5794$ & $\$ 394$ & $\$ 169$ \\
MIROC5 & $\$ 1275$ & $\$ 192$ & $\$ 112$ \\
5-GCM average & $\$ 1990$ & $\$ 212$ & $\$ 127$ \\
RCP8.5 & & & $\$ 129$ \\
CanESM & $\$ 3284$ & $\$ 292$ & $\$ 157$ \\
CCSM4 & $\$ 4026$ & $\$ 347$ & $\$ 81$ \\
GISSE2R & $\$ 784$ & $\$ 127$ & $\$ 224$ \\
HadGEM2ES & $\$ 8824$ & $\$ 684$ & $\$ 123$ \\
MIROC5 & $\$ 2169$ & $\$ 258$ & $\$ 143$ \\
5-GCM average & $\$ 3817$ & $\$ 342$ &
\end{tabular}

Note: All estimates in this table are inclusive of baseline costs. All estimates adjusted for population and GDP growth over the simulation period

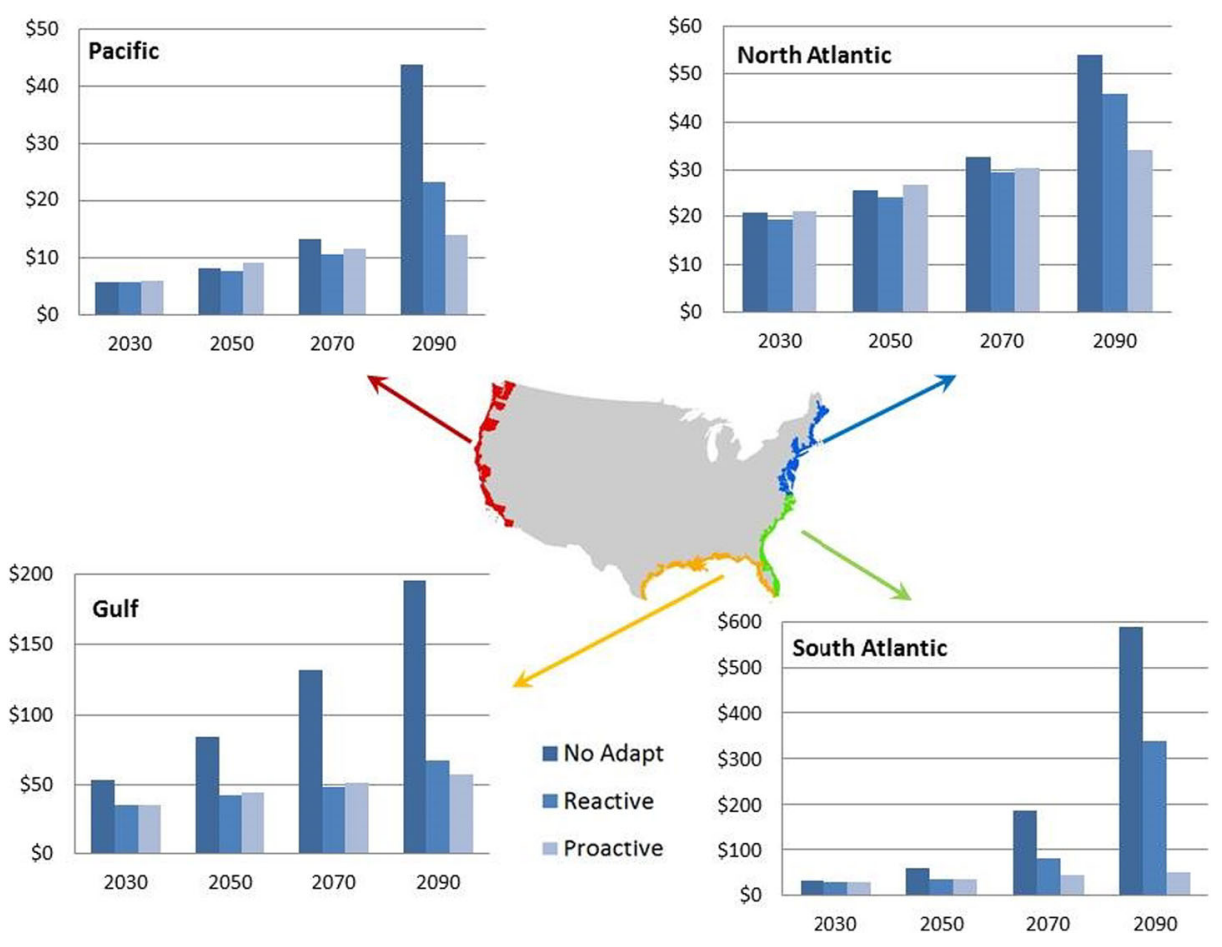

Fig. 3 Total era-level (20 years) coastal property costs (billions \$2018, undiscounted) for RCP8.5, undiscounted for four coastal regions_-Pacific, North Atlantic, South Atlantic, and the Gulf-as well as the three adaptation scenarios: No Adaptation, Reactive, and Proactive 
Reactive Adaptation scenario allows for moderate reductions in costs to about $75 \%$ of No Adaptation scenario costs in 2090, while a proactive strategy reduces costs to about $9 \%$. Sea walls built in the Proactive Adaptation scenario earlier in the century stagnates cost growth in the latter half by protecting property further from the coast that are not economically efficient to elevate.

In the Gulf, SS damage has a greater influence than in the other regions by 2090 , accounting for $65 \%$ of the costs in No Adaptation scenario under RCP8.5 (other regions are less than 40\%). As a result, property elevation (used in the Reactive Adaptation scenario in response to SS damage) is more effective to reduce these costs, to about $20 \%$ of the SS costs in No Adaptation scenario by 2090. Also, as discussed in Section 3.7.4, model initiation plays a role in the resulting costs. This initiation likely overestimates the amount of protection currently in place, especially in the Gulf where more sea walls are estimated to exist in the model initiation than in any other region-doubling the South Atlantic region. Costs associated with the planning, installation, and maintenance of these protective structures are not included in the totals reported herein. Since these structures effectively protect properties further inland under all three adaptation scenarios, costs and damages in the Gulf are likely underestimated, and to a higher degree than other regions.

Costs are lowest in the Pacific, where much of the coastal properties are protected by higher relative elevations and coastal cliffs. Also, regional SLR in the Pacific Northwest is lower compared to other regions because of glacial shrinkage in Alaska, which causes isostatic rebound in the Pacific Northwest (Sweet et al. 2017b). The majority of the costs occur in southern California and the San Francisco Bay area. Three counties (Orange, Los Angeles, and San Diego) make up about $57 \%$ of the total discounted costs under RCP8.5 and the No Adaptation scenario. The No Adaptation and Reactive Adaptation scenarios show similar costs out to 2090, suggesting that local property adaptation through elevation in response to SS does not provide a substantial reduction in costs. A proactive strategy, however, does allow for significant reductions.

In the North Atlantic, costs are relatively high in 2030, but rise slower toward the end of the century than other regions. Much of the properties in the North Atlantic are either protected in the model initiation (e.g., Long Island, New Jersey), or built on higher elevations than in the South Atlantic or the Gulf, where coastal areas are flatter with less elevation gain inland. Although armoring is built in the Proactive scenario in the region, it is less effective at reducing SS damage than in the South Atlantic and the Gulf due to a more complicated topography.

Figure 4 shows the relative adaptation cost effectiveness for each coastal county. The adaptation effectiveness is calculated as follows:

$$
\text { Adapt. Effect. }=\left(1-\frac{\text { Proactive }}{\text { No Adapt }}\right) \times 100 \%
$$

where No Adaptation and Proactive Adaptation scenarios are the total costs from 2020 to 2099 , discounted with a $3 \%$ discount rate. The value is meant to show the savings with a proactive strategy as opposed to a No Adaptation scenario strategy. The counties in darker brown are those where adaptation is most effective.

Southern Florida shows substantial reductions in costs from adaptive measures where most counties show Proactive Adaptation scenario to be less than a quarter of costs projected under the No Adaptation scenario. However, building effective sea walls in southern Florida may be 


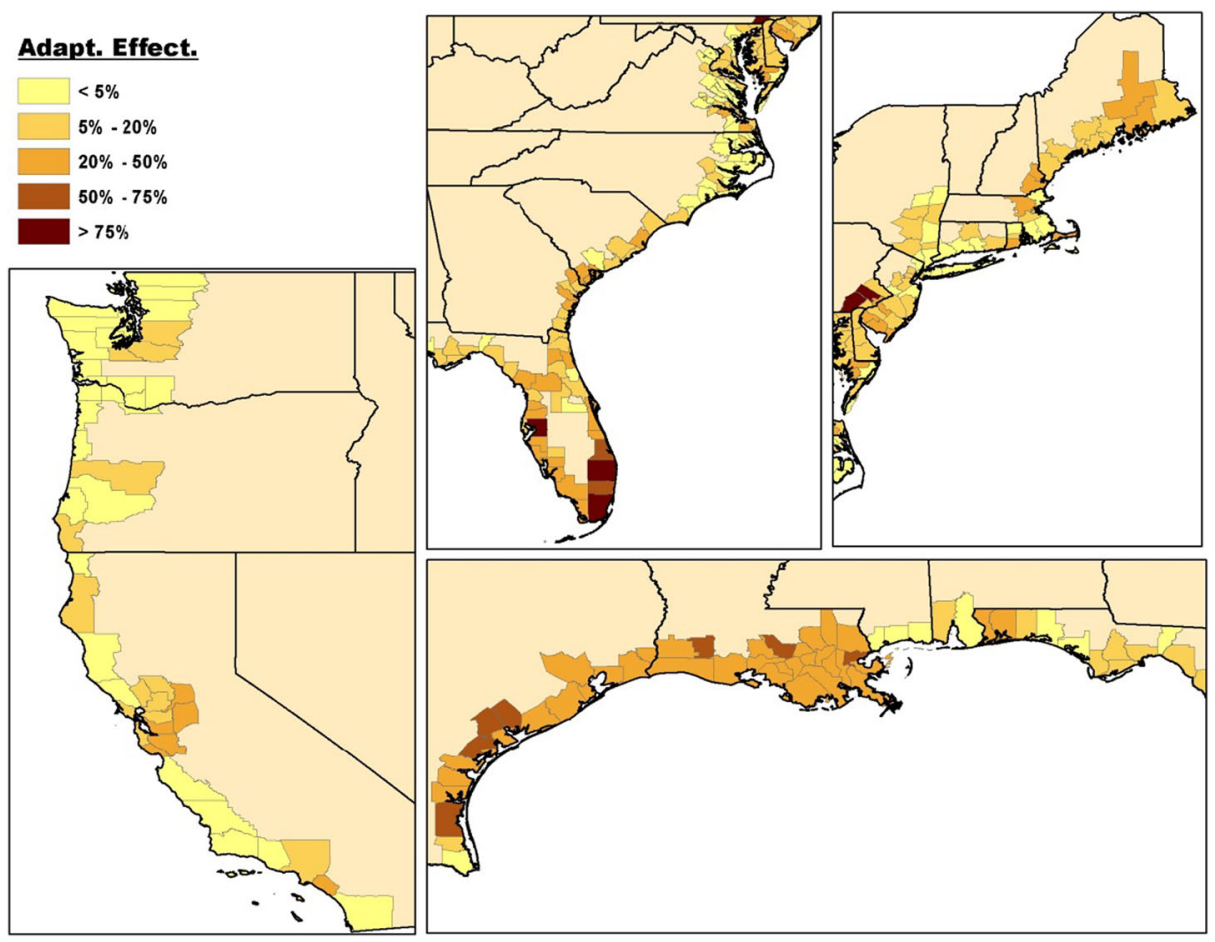

Fig. 4 Coastal adaptation cost effectiveness for RCP8.5. These values represent an index of the savings from adopting Proactive Adaptation scenario as opposed to a No Adaptation scenario, shown as a $\%$ of total No Adaptation costs, using a 3\% discount rate, total over 2020-2099. Darker areas indicate a higher potential for cost-effective adaptation to minimize the total of residual damages and adaptation costs

challenging because the karst limestone in the area is known to cause seepage or even sinkholes (Reich et al. 2009). The NCPM does not take into consideration these locationspecific technical challenges for the applicability of the different protection options.

Adaptation is comparatively less effective in the North Atlantic than in southern Florida. Along the Gulf, proactive adaptation is most effective in Texas and Louisiana. In the Pacific, adaptation is moderately effective in Southern California - specifically, Orange County and Los Angeles - where a large portion of the costs are incurred in the region. Adaptation is also moderately effective in the San Francisco Bay area.

Although about two-thirds of counties show proactive adaptation cost effectiveness less than $20 \%$, national adaptation cost effectiveness is estimated at $51 \%$ for RCP8.5 and $37 \%$ for RCP4.5 using discounted costs (at a 3\% rate) and 67\% for RCP8.5 and 51\% for RCP4.5 using undiscounted costs. This shows that a proactive adaptation strategy is effective in parts of the country that are expected to have the greatest costs, e.g., southern Florida. In addition, proactive adaptation is more effective for higher SLR projections.

\section{Discussion and conclusions}

Results presented in the preceding sections provide new evidence of the vulnerability of US rail, road, and coastal infrastructure to multiple climate stressors, filling an important gap in our 
understanding of potential costs in scenarios with and without future climate mitigation and adaptation. Lack of action on both fronts is expected to lead to costs in the range of $\$ 100 \mathrm{~s}$ of billions annually by the end of this century, dominated by costs in the road sector, with important but more geographically limited impacts in the coastal property and rail sectors. These new estimates make clear that adaptation inaction is likely to lead to enormous damages to infrastructure users, particular road users.

The results also make clear that the benefits of action, for both adaptation and greenhouse gas emissions mitigation, are large, even if there appears to be little potential to completely eliminate residual damage and costs with the most expansive adaptation plans. The first (reactive) tier of adaptation action reduces costs by a factor of 10, with the largest returns on adaptation investment in the roads sector, and the second (proactive) tier reduces total costs across all three sectors to the low $\$ 10$ s of billions annually. Altering the emissions trajectory from RCP8.5 to RCP4.5, also has high potential to reduce costs, by a factor of 2 for the larger roads and coastal sectors, and by a factor of 5 for the rail sector. Furthermore, adaptation and mitigation action together provide the largest benefits - and, interestingly, proactive adaptation action is a remarkably cost-effective insurance policy, reducing effects under both RCPs to less than $\$ 10$ billion annually in each sector in 2090. This "residual damage" after adaptation remains a substantial sum but is far less than the potential damages if no action is taken. These results are tempered somewhat by our adoption of an optimal adaptation framework in the Proactive scenario case, which assume well-timed investments to protect infrastructure, which can be difficult to implement in reality. In the coastal sector in particular, adaptation decisions follow a near-optimal decision rule although without perfect foresight. Studies have suggested that individual's flood risk choices do not follow rational economic assumptions (Bubeck, 2014; Poussin et al. 2014). Relaxation of this optimal decision rule assumption is explored in some depth in Lorie et al. (2020), and the result yields an increase in damages relative to the Proactive scenario case considered here. As a result, the most "realistic" scenario for adaptation possibly lies between the Reactive and Proactive scenario cases, for all sectors.

Our overall results also illustrate that both the vulnerabilities and the potential for adaptation action to reduce those vulnerabilities vary substantially across the USA (Figures 1, 2, and 3). Our framework thus has the potential to provide adaptation planners with better information on the regional scale, with possible applications of the overall framework (with more detailed physical and cost inputs) to the local scale. At the national scale, US Federal agencies could make use of the detailed spatial results that underly Figures 1, 2, and 3 to target future climate resilience investments in these sectors. State agencies could similarly identify specific vulnerabilities and opportunities for the most cost-effective adaptation options - but both Federal and state agencies should also be cognizant of the potential for unintended consequences to disadvantaged and socially vulnerable populations from the application of a strict benefit-cost test for adaptation investments (Martinich et al. 2013; Moss et al. 2019). Such analyses would add to understanding of the benefits and limits of adaptation with considerations of local climate stressor manifestation and first-order characteristics that affect vulnerability and adaptation efficacy - recent reviews suggest this is an important need (Jacobs et al. 2018a; Wang et al. 2020). Our approach falls short of what is needed to engineer on a site-specific project basisfor example, we do not assess the potential for groundwater rise behind sea-walls to affect otherwise protected infrastructure (see Jacobs et al. 2018a; Knott et al. 2017) - but is wellsuited for understanding the magnitude and, perhaps, spatial and temporal allocation of adaptation resources that may be incorporated in new infrastructure financing program. Owing to computational constraints, our work in the USA also has yet to adopt a robust-decision 
making framework, which seeks to minimize the potential for regrets of over- or underinvesting in long-lived resilient infrastructure in the face of future climate change uncertainty. This framework has been demonstrated in some international contexts (Cervigni et al. 2016), at the African continent scale, and the results provided the basis for more focused analyses in Ethiopia and Kenya that are currently in development, but have yet to be applied in the US infrastructure sector, except in water resources (see Fischbach et al. 2020 for an example).

Infrastructure has always been vulnerable to natural hazards and will continue to be under heightened climate risks. The critical need, however, is for an assessment and planning methodology such as this that incorporates a range of climate forecasts with a high degree of spatial resolution, across multiple stressors, and provides a capability to assess cost/benefit trade-offs across a range of adaptation efforts. Such an approach has the potential to inform decision-makers on strategies that can be employed to improve the reliability of infrastructure service delivery in the face of a changing natural hazard landscape.

Within our analyses, there remain important uncertainties associated with assessing vulnerabilities and adaptation options at national scale, when important processes and adaptation decision-making are at a finer scale that is unrealistic to replicate for our geographic scope. Pilot studies at finer state and local scale sponsored by DOT for transport, and NOAA for coastal analyses, will fill a critical role in informing the magnitude and direction of uncertainties, and insights from that emerging work have potential to further improve these methods (see Jacobs et al. 2018a for a summary of DOT's program). An important uncertainty in our work remains the inability to capture the broad scope of primary and secondary effects of climate on transport systems. While prior quantitative work has largely focused on either repair costs (e.g., Underwood et al. 2017, but only for road pavement), or on user delay costs (Ganin et al. 2017 for flood risk to roads in 40 urban areas; Schuldt et al. 2021 for all construction delays), both direct and indirect costs are important, and often there are tradeoffs between the two. Strategies to minimize adaptation costs, for example, may run the risk of dramatically increasing user costs (as our No Adaptation scenario results suggest). Our work begins to fill that gap by considering both direct and indirect costs in the road and rail sectors, in an integrated fashion, but many costs remain unquantified. For example, in the coastal sector, indirect costs such as losses in recreation from eroded beaches or nuisance flooding causing regular road interruptions are not yet taken into account (Jacobs et al. 2018b). In addition, our initialization procedure in this sector (spinup) is likely to overestimate existing protection and thereby underestimates the incremental costs of climate change overall, especially for the No Adaptation scenario - see Supplemental Material for details.

In the road and rail sectors, there is a need for more rigorous exploration of climate-related stressors beyond temperature and precipitation, including wildfires and dust storm effects on visibility and transport delays, in addition to the potential for winter events to moderate or, in some contexts, worsen. Our model's omission of winter road clearing and maintenance costs, for example, likely represents an overestimation bias, as these costs are likely to moderate with higher temperatures. In addition, while we quantify the first-order effects of transport delays, we are not yet capable of estimating how transport delays may lead to other secondary costs, such as lost productivity in multiple economic sectors. The next frontier of infrastructure analyses needs also to explore the integration of cross-sectoral analyses. For example, roads and rail are part of an integrated system of demand for mobility for people and goods which might be considered jointly, and coastal infrastructure relies critically on road and even rail infrastructure to maintain economic viability (Sun et al. 2020 provides one example). The potential for important insights as these literatures expand scope and integrate across sectors remains enormous. 
Supplementary Information The online version contains supplementary material available at https://doi.org/ 10.1007/s10584-021-03179-w.

Acknowledgements We wish to thank Lisa Rennels and Natalie Weiss for able research assistance.

Author contribution J.N. and J.M. conceived and coordinated the work; J.M., J.N., K.S., and P.C. developed the methodology; M.B. and J.H. carried out the rail and road analyses; J.N. and C.F. carried out the coastal property analysis; and M.B., J.N., J.H., P.C., and C.F. wrote the manuscript.

Funding This research was funded by the EPA under contract EP-D-14-032. The views expressed in this document are those of the authors and do not necessarily reflect those of their affiliated institutions, including the EPA.

\section{References}

American Society of Civil Engineers (ASCE). 2017. 2017 Infrastructure report card: a comprehensive assessment of America's infrastructure. http://www.infrastructurereportcard.org

Ara, Inc. (Applied Research Associates), 2001. Guide for mechanistic-empirical design of new and rehabilitated pavement structures. Final Document, Appendix Oo-1: background and preliminary smoothness prediction models for flexible pavements. Prepared for: National Cooperative Highway Research Program, Transportation Research Board, National Research Council. February 2001.

ASCE. 2018. Climate-resilient infrastructure: adaptive design and risk management. Committee on Adaptation to a Changing Climate; Edited by Bilal M. Ayyub. https://doi.org/10.1061/9780784415191

Barnes G, Langworthy P (2004) Per mile costs of operating automobiles and trucks. Transportation Research Record. 1864(1):71-77. https://doi.org/10.3141/1864-10

Cervigni, R., A. M. Losos, J.E.Neumann, P. Chinowsky, Paul. 2016. Enhancing the climate resilience of Africa's infrastructure: the roads and bridges sector (English). Washington, D.C.: World Bank Group. http:// documents.worldbank.org/curated/en/270671478809724744/Enhancing-the-climate-resilience-of-Africa-sInfrastructure-the-roads-and-bridges-sector

Chinowsky P, Price J, Neumann J (2013) Assessment of climate change adaptation costs for the U.S. road network. Glob Environ Chang 23(4):764-773

Chinowsky P, Helman J, Gulati S, Neumann J, Martinich J (2017) Impacts of climate change on operation of the US rail network. Transport Policy. https://doi.org/10.1016/j.tranpol.2017.05.007

Fischbach JR, Wilson MT, Bond CA, Kochhar AK, Catt D, Tierney D (2020) Managing heavy rainfall with green infrastructure: an evaluation in Pittsburgh's Negley Run Watershed. RAND Corporation, Santa Monica, CA https://www.rand.org/pubs/research_reports/RRA564-1.html

Fleming, E., J. Payne, W. Sweet, M. Craghan, J. Haines, J.F. Hart, H. Stiller, and A. Sutton-Grier, 2018: Coastal effects. In Impacts, risks, and adaptation in the United States: fourth national climate assessment, Volume II [Reidmiller, D.R., C.W. Avery, D.R. Easterling, K.E. Kunkel, K.L.M. Lewis, T.K. Maycock, and B.C. Stewart (eds.)]. U.S. global change research program, Washington, DC, USA, pp. 322-352. doi: https://doi. org/10.7930/NCA4.2018.CH8

Ganin AA, Kitsak M, Marchese D, Keisler JM, Seager T, Linkov I (2017) Resilience and efficiency in transportation networks. Science Advances 3:e1701079

Gordian. 2017. Heavy construction costs with RSMeans Data 2017. Transportation.

Hall, J. and K. Jenkins. n.d. Modeling the impacts of climate change on cities: economic costs of rail buckle events. Arcadia Factsheet 9. https://arcc.ouce.ox.ac.uk/wp-content/pdfs/ARCADIA-09-buckling.pdf

Jacobs, J.M., M. Culp, L. Cattaneo, P. Chinowsky, A. Choate, S. DesRoches, S. Douglass, and R. Miller, 2018a: Transportation. In Impacts, risks, and adaptation in the United States: fourth national climate assessment, Volume II [Reidmiller, D.R., C.W. Avery, D.R. Easterling, K.E. Kunkel, K.L.M. Lewis, T.K. Maycock, and B.C. Stewart (eds.)]. U.S. Global Change Research Program, Washington, DC, USA, pp. 479-511. doi: https://doi.org/10.7930/NCA4.2018.CH12

Jacobs JM, Cattaneo LR, Sweet W, Mansfield T (2018b) Recent and future outlooks for nuisance flooding impacts on roadways on the US East Coast. Transportation Research Record. https://doi.org/10.1177/ 0361198118756366

Kish, A. and G. Samavedam. 2013. Track buckling prevention: theory, safety concepts, and applications. U.S. DOT, Federal Railroad Administration. DOT/FRA/ORD-13/16. 
Knott JF, Elshaer M, Daniel JS, Jacobs JM, Kirshen P (2017) Assessing the effects of rising groundwater from sea level rise on the service life of pavements in coastal road infrastructure. Transportation Research Record: Journal of the Transportation Research Board 2639:1-10. https://doi.org/10.3141/2639-01

Kopp RE, Horton RM, Little CM, Mitrovica JX, Oppenheimer M, Rasmussen DJ, Strauss BH, Tebaldi C (2014) Probabilistic 21st and 22nd century sea-level projections at a global network of tide-gauge sites. Earth's Future 2:383-406. https://doi.org/10.1002/2014EF000239

Lorie M, Neumann JE, Sarofim MC, Jones R, Horton RM, Kopp RE, Fant C, Wobus C, Martinich J, O’Grady M, Gentile LE (2020) Modeling coastal flood risk and adaptation response under future climate conditions. Climate Risk Management 29. https://doi.org/10.1016/j.crm.2020.100233

Martinich J, Crimmins A (2019) Climate damages and adaptation potential across diverse sectors of the United States. Nat. Clim. Change 9:397-404

Martinich J, Neumann J, Ludwig L, Jantarasami L (2013) Risks of sea level rise to disadvantaged communities in the United States. Mitig Adapt Strateg Glob Change 18:169. https://doi.org/10.1007/s11027-011-9356-0

Maxwell, K., S. Julius, A. Grambsch, A. Kosmal, L. Larson, and N. Sonti, 2018: Built Environment, Urban Systems, and Cities. In Impacts, risks, and adaptation in the United States: fourth national climate assessment, Volume II [Reidmiller, D.R., C.W. Avery, D.R. Easterling, K.E. Kunkel, K.L.M. Lewis, T.K. Maycock, and B.C. Stewart (eds.)]. U.S. Global Change Research Program, Washington, DC, USA, pp. 438-478. doi: https://doi.org/10.7930/NCA4.2018.CH11

Moss RH, Avery S, Baja K, Burkett M, Chischilly AM, Dell J, Fleming PA, Geil K, Jacobs K, Jones A, Knowlton K, Koh J, Lemos MC, Melillo J, Pandya R, Richmond TC, Scarlett L, Snyder J, Stults M, Waple A, Whitehead J, Zarrilli D, Fox J, Ganguly A, Joppa L, Julius S, Kirshen P, Kreutter R, McGovern A, Meyer R, Neumann J, Solecki W, Smith J, Tissot P, Yohe G, Zimmerman R (2019) Evaluating knowledge to support climate action: a framework for sustained assessment. Wea. Climate Soc. 11:465-487. https://doi. org/10.1175/WCAS-D-18-0134.1

Neumann J, Price J, Chinowsky P, Wright L, Ludwig L, Streeter R, Jones R, Smith JB, Perkins W, Jantarasami L, Martinich J (2015a) Climate change risks to US infrastructure: impacts on roads, bridges, coastal development, and urban drainage. Climatic Change 131:97-109

Neumann J, Emanuel K, Ravela S, Ludwig L, Kirshen P, Bosma K, Martinich J (2015b) Joint effects of storm surge and sea-level rise on US coasts: new economic estimates of impacts, adaptation, and benefits of mitigation policy. Climatic Change 129:337-349

NOAA (National Oceanic and Atmospheric Administration). 2018. NOAA Tides and Currents - Water Levels. Available at https://tidesandcurrents.noaa.gov/stations.html?type=Water+Levels. Accessed June 2018.

Poussin JK, Botzen WW, Aerts JC (2014) Factors of influence on flood damage mitigation behaviour by households. Environmental Science \& Policy 40:69-77

Qiao Y, Flintsch G, Dawson A, Parry T (2013) Examining effects of climatic factors on flexible pavement performance and service life. Transportation Research Record. Journal of the Transportation Research Board 2349:100-107. https://doi.org/10.3141/2349-12

Reich, C.D, P.W. Swarzenski, W.J. Greenwood, D.S. Wiese. 2009: Investigation of coastal hydrogeology utilizing geophysical and geochemical tools along the Broward County Coast, Florida. U.S. Geological Survey Open-File Report 2008-1364, 21 p., plus apps. A-C.

Schuldt SJ, Nicholson MR, Adams YA II, Delorit JD (2021) Weather-related construction delays in a changing climate: a systematic state-of-the-art review. Sustainability 13:2861. https://doi.org/10.3390/su13052861

Sun J, Chow ACH, Madanat SM (2020) Multimodal transportation system protection against sea level rise. Transportation Research Part D: Transport and Environment 88:102568. https://doi.org/10.1016/j.trd.2020.102568

Sweet, W.V., R.E. Kopp, C.P. Weaver, J. Obeysekera, R.M. Horton, E.R. Thieler, and C. Zervas, 2017a: Global and Regional Sea Level Rise Scenarios for the United States. NOAA Technical Report NOS CO-OPS 083. NOAA/NOS Center for Operational Oceanographic Products and Services

Sweet, W.V., R. Horton, R.E. Kopp, A.N. LeGrande, and A. Romanou, 2017b: Sea level rise. In: Climate Science Special Report: Fourth National Climate Assessment, Volume I [Wuebbles, D.J., D.W. Fahey, K.A. Hibbard, D.J. Dokken, B.C. Stewart, and T.K. Maycock (eds.)]. U.S. Global Change Research Program, Washington, DC, USA, pp. 333-363, doi: https://doi.org/10.7930/J0VM49F2.

U.S. Bureau of Reclamation, Climate Analytics Group, Climate Central, Lawrence Livermore National Laboratory, Santa Clara University, Scripps Institution of Oceanography, U.S. Army Corps of Engineers, and U.S. Geological Survey, 2016: Downscaled CMIP3 and CMIP5 Climate Projections: Release of Downscaled CMIP5 Climate Projections, Comparison with Preceding Information, and Summary of User Needs. Data available at http://gdo-dcp.ucllnl.org/downscaled_cmip_projections/.

U.S. DOT. 2015. Climate change adaptation support for transportation practitioners. 2013 Volpe Center Innovation Challenge Project. Jon Cybulski, Kristin Lewis, Kevin McCoy, Ben Rasmussen. 
U.S. DOT. 2016. Revised Departmental Guidance on Valuation of Travel Time in Economic Analysis. Downloaded from https://www.transportation.gov/sites/dot.gov/files/docs/2016\%20Revised\%20Value\% 20of\%20Travel\%20Time\%20Guidance.pdf

U.S. Environmental Protection Agency (EPA). 2015. Climate Change in the United States; Benefits of Global Action. United States Environmental Protection Agency, Office of Atmospheric Programs, EPA 430-R-15001.

U.S. EPA (2017) Multi-model framework for quantitative sectoral impacts analysis: a technical report for the fourth national climate assessment. U.S. Environmental Protection Agency, Washington, D.C.

U.S. Global Change Research Program (USGCRP), 2017: climate change impacts in the United States

Underwood BS, Guido Z, Gudipudi P, Feinberg Y (2017) Increased costs to US pavement infrastructure from future temperature rise. Nature Climate Change 7:704-710

Wang, T., Harvey, J., Lea, J. D, \& Kim, C. (2013). Impact of pavement roughness on vehicle free-flow speed. UC Davis: University of California Pavement Research Center.

Wang T, Qu Z, Yang Z, Nichol T, Clarke G, Ge Y-E (2020) Climate change research on transportation systems: climate risks, adaptation and planning. Transportation Research Part D 88:102553. https://doi.org/10.1016/j. $\operatorname{trd} .2020 .102553$

Publisher's note Springer Nature remains neutral with regard to jurisdictional claims in published maps and institutional affiliations. 